\title{
DNA damage response at telomeres boosts the transcription of SARS-CoV-2 receptor ACE2 during aging
}

\author{
Sara Sepe $e^{1, \dagger}\left(\mathbb{D}\right.$, Francesca Rossiello ${ }^{1, \dagger}$ (D) , Valeria Cancila ${ }^{2}$, Fabio Iannelli ${ }^{1}$ D, Valentina Matti ${ }^{1}$,

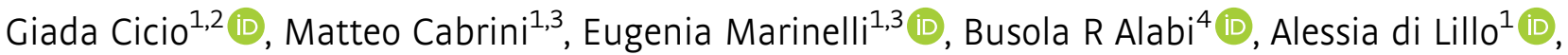 \\ Arianna Di Napoli ${ }^{5}$ (iD, Jerry W Shay ${ }^{4}$ (D) Claudio Tripodo ${ }^{2}$ (D) \& Fabrizio d'Adda di Fagagna ${ }^{1,3, *}$ (iD
}

\begin{abstract}
The severe acute respiratory syndrome coronavirus 2 (SARS-CoV-2) causes the coronavirus disease 2019 (COVID-19), known to be more common in the elderly, who also show more severe symptoms and are at higher risk of hospitalization and death. Here, we show that the expression of the angiotensin converting enzyme 2 (ACE2), the SARS-CoV-2 cell receptor, increases during aging in mouse and human lungs. ACE2 expression increases upon telomere shortening or dysfunction in both cultured mammalian cells and in vivo in mice. This increase is controlled at the transcriptional level, and Ace 2 promoter activity is DNA damage response (DDR)-dependent. Both pharmacological global DDR inhibition of ATM kinase activity and selective telomeric DDR inhibition by the use of antisense oligonucleotides prevent Ace2 upregulation following telomere damage in cultured cells and in mice. We propose that during aging telomere dysfunction due to telomeric shortening or damage triggers DDR activation and this causes the upregulation of ACE2, the SARS-CoV-2 cell receptor, thus contributing to make the elderly more susceptible to the infection.
\end{abstract}

Keywords Ace2; aging; COVID-19; DNA damage response; telomere Subject Categories DNA Replication, Recombination \& Repair; Microbiology, Virology \& Host Pathogen Interaction; Molecular Biology of Disease DOI 10.15252/embr.202153658 | Received 21 July 2021 | Revised 11 November 2021 | Accepted 15 November 2021

EMBO Reports (2021) e53658

\section{Introduction}

The severe acute respiratory syndrome coronavirus 2 (SARS-CoV-2) is responsible for the recent coronavirus disease 2019 (COVID-19) pandemic. Patients infected by SARS-CoV-2 show a range of symptoms including dry cough, fever, headache, dyspnea, and pneumonia with an estimated mortality rate ranging from 3 to $5 \%$ (Huang et al, 2020; Wang et al, 2020).

Recent studies highlighted the important role of the human angiotensin converting enzyme 2 (ACE2) molecule, a regulator of the renin-angiotensin system (RAS), in mediating cell entry of SARS-CoV-2 (Hoffmann et al, 2020; Lan et al, 2020; Walls et al, 2020; Yan et al, 2020). This mechanism is conserved in other viruses, including the closely related SARS-CoV, although SARSCoV-2 has a ten times higher affinity to ACE2, which is consistent with its higher infectiousness (Hoffmann et al, 2020; Zhou et al, 2020). Indeed, HeLa cells become susceptible to SARS-CoV-2 infection only if expressing ACE2 (Zhou et al, 2020). These findings indicate that binding to the ACE2 receptor is a critical initial step for SARS-CoV-2 to infect target cells and is crucial for human infection and that the expression and distribution of the ACE2 receptor may be relevant for the progression and prognosis of COVID-19. An analysis of single-cell RNA sequencing data obtained from 43,134 human lung cells revealed that only $0.64 \%$ of cells in lungs express Ace2, which was mostly found on the surface of alveolar epithelial type II cells (ATII). Other types of cells, including alveolar epithelial type I cells (ATI), airway epithelial cells, fibroblasts, endothelial cells, and macrophages, also express ACE2 but at lower levels (Zhao et al, 2020). This indicates that ATII cells are likely to be the primary target of SARS-CoV-2 infection in the lungs. Since SARSCoV-2 mainly spreads via respiratory droplets, and ACE2 is mostly expressed by ATII cells, the lung is the first target organ for SARSCoV-2 infection, and indeed, pneumonia is the most common complication seen in COVID-19 patients with an occurrence of 91.1\% (Guan et al, 2020).

The severity of the infection correlates with the age of patients, suggesting that aging is an important risk factor influencing the

\footnotetext{
1 IFOM Foundation-FIRC Institute of Molecular Oncology Foundation, Milan, Italy

2 Tumor Immunology Unit, Department of Health Sciences, University of Palermo, Palermo, Italy

3 Istituto di Genetica Molecolare, Consiglio Nazionale delle Ricerche (IGM-CNR), Pavia, Italy

4 Department of Cell Biology, University of Texas Southwestern Medical Center, Dallas, TX, USA

5 Department of Clinical and Molecular Medicine, Pathology Unit, Sant'Andrea Hospital, Sapienza University, Rome, Italy

*Corresponding author. Tel: +3902 574303227; E-mail: fabrizio.dadda@ifom.eu

†These authors contributed equally to this work.
} 
outcome of the disease (Verity et al, 2020). According to a study of 1,099 patients with COVID-19, the average age of the patients that develop severe symptoms was significantly higher than the age of those with non-severe symptoms (Wang et al, 2020). Among the COVID-19 patients with severe symptoms, the age of non-survivors (64.6 years) was higher than the survivors (51.9 years) (Verity et al, 2020). These results indicate that aging correlates with the severity of pathological progression and poor prognosis of COVID-19. The reasons for the development of severe symptoms in the elderly compared with young individuals are still under intense investigation. ACE2 expression has been positively related to patients' age (Lukassen et al, 2020; Beyerstedt et al, 2021). Indeed, there is evidence showing age-dependent expression of ACE2 in nasal epithelium, the first point of contact for SARS-CoV-2 (Bunyavanich et al, 2020). Lower ACE2 expression in children relative to adults may help explain why COVID-19 is less prevalent in children (Lingappan et al, 2020). These results were also confirmed experimentally in mice, with ACE2 expression increasing with age in different organs, including lungs (Yee et al, 2020). However, some reports have questioned the increase in ACE2 levels in lung during aging (Xudong et al, 2006; Chen et al, 2020). Since age-dependent ACE2 expression is a feature conserved across species, mouse models can be used to further investigate this phenomenon and to elucidate the underlying molecular mechanisms, and design possible interventions.

During aging, telomeres progressively shorten and/or accumulate damage in several tissues and organs in different species including humans (Demanelis et al, 2020; Vaiserman \& Krasnienkov, 2021). Telomeres are the regions at the ends of linear chromosomes and in vertebrates are composed of large track of canonical TTAGGG repeats. A protein complex named shelterin is bound to telomeric DNA and protects it from being recognized as DNA damage (DD), thus preventing DNA damage responses (DDR) (Palm \& De Lange, 2008). Standard DNA polymerases cannot fully replicate linear DNA templates; thus, in the absence of the reverse transcriptase telomerase and also due to additional exonucleolytic activities, DNA replication results in the generation of chromosomes with progressively shortened telomeres (Harley et al, 1990). When telomeres become critically short, they are sensed as DNA doublestranded breaks (DSBs) and activate DDR pathways (d'Adda di Fagagna et al, 2003; Herbig et al, 2004). This involves the activation of protein kinase ataxia telangiectasia mutated (ATM), which phosphorylates the histone variant H2AX at serine 139 (named $\gamma \mathrm{H} 2 \mathrm{AX}$ ), favoring the secondary recruitment of additional DDR factors including p53-binding protein 1 (53BP1) to form so-called DDR foci (Polo \& Jackson, 2011; Dantuma \& van Attikum, 2016).

Non-coding RNA is emerging as a novel key regulator of the DDR pathways. Damage-induced long non-coding RNAs (dilncRNAs) and their processed forms named DNA damage response RNAs (DDRNAs) are generated at sites of DSBs, and they are necessary for full DDR activation, as demonstrated by the observation that antisense oligonucleotides (ASOs) against them inhibit DDR foci formation downstream of $\gamma \mathrm{H} 2 \mathrm{AX}$ (Francia et al, 2012; Michelini et al, 2017; Pessina et al, 2019). Similar to DSBs, telomere dysfunction induces their transcription and inhibition of telomeric ncRNA (tncRNA) by sequence-specific telomeric ASOs (tASOs) prevents DDR activation in cultured cells and in vivo in mice (Rossiello et al, 2017).

The impact of telomere shortening on organismal aging in animal models has been studied upon genetic inactivation of telomerase, for instance by deletion of the RNA component Terc $\left(\mathrm{Terc}^{-/}\right.$) in mice. Successive inbreedings of these mice lead to progressive telomere shortening and DDR activation at telomeres, and the accumulation of features of aging and aging-related diseases (Blasco et al, 1997). In addition, telomeres are prone to accumulate DNA damage and markers of DDR activation independently from their length (Fumagalli et al, 2012; Hewitt et al, 2012). This is also because telomeric DNA is more prone to oxidative DNA damage (8oxodG) (Barnes et al, 2019), and since damage at telomeres is less repairable, this causes persistent DD and protracted DDR activation (Fumagalli et al, 2012).

In the present study, we aimed to better characterize the regulation of ACE2 expression during aging following telomere shortening and DDR activation.

\section{Results and Discussion}

In order to better characterize the modulation of ACE2 expression during aging, and the underlying potential molecular mechanisms, we studied the expression of ACE2 in mouse and human lungs at different ages.

Figure 1. ACE2 expression increases during aging in mouse and human lungs.

A RT-qPCR detection of Ace2 mRNA expression levels in lungs from young (2-3 months) and old (22-24 months) mice ( $n=7$ mice per group).

B Representative microphotographs and quantitative analyses of ACE2 immunohistochemical staining in lungs from young ( 2 months) and old ( 22 months) mice ( $n=3$ mice per group). Scale bar, $200 \mu \mathrm{m}$.

C Representative microphotographs and quantitative analyses of ACE2 immunohistochemical staining in lung parenchyma of young (20-35 years old) and old (60-80 years old) humans ( $n=4-7$ individuals per group). Scale bar, $200 \mu \mathrm{m}$.

D Double-marker immunofluorescence and quantitative analyses of ACE2 intensity level in pro-SP-C-positive type II pneumocytic and CD31-positive endothelia in lungs from young and old mice ( $n=3-6$ mice per group). Scale bar, $100 \mu$ m. a.u. = arbitrary units.

E Double-marker immunofluorescence and quantitative analyses of ACE2 intensity level in TTF-1-positive type II pneumocytic and CD31-positive endothelia in lungs from young and old humans ( $n=4-7$ individuals per group). Scale bar, $100 \mu$ m. a.u. = arbitrary units.

F Single-cell transcriptomic data from aging tissues in the mouse lung from Tabula Muris Senis. Upper left panel: uniform manifold approximation and projection (UMAP) of cell identity with ATII cells represented as red dots. Upper right panel: dot plot of Ace2 expression according to age (young = 3 months; old $=30$ months). Dot size represents fraction of cells expressing a given gene. Lower panel: UMAP of Ace2 expressing cells depicted as blue dots.

Data information: In (A-E), data are presented as mean \pm SEM. ${ }^{*} P<0.05,{ }^{* \star *} P<0.001$ two-sided unpaired Student's $t$-test. 
A

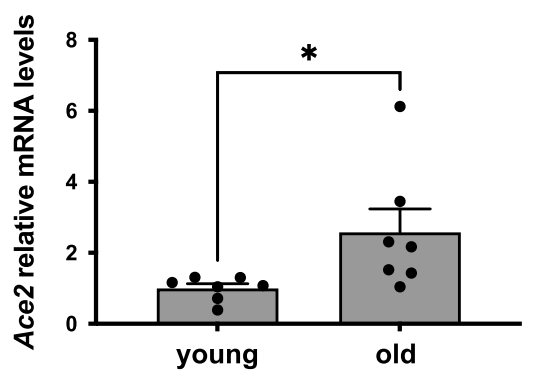

C

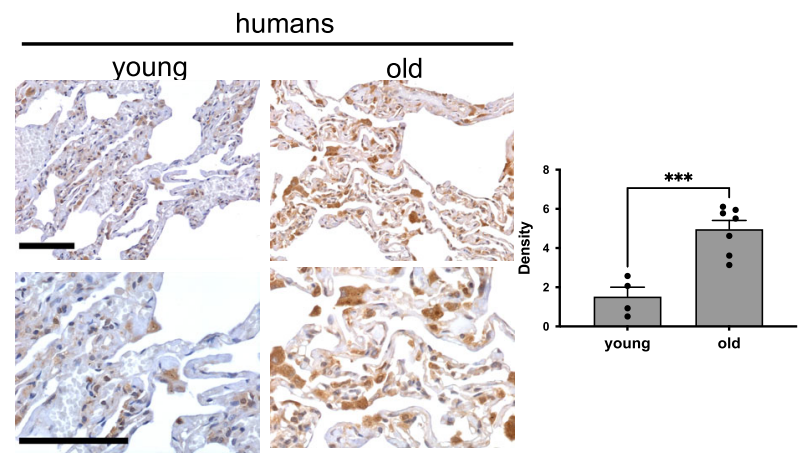

E
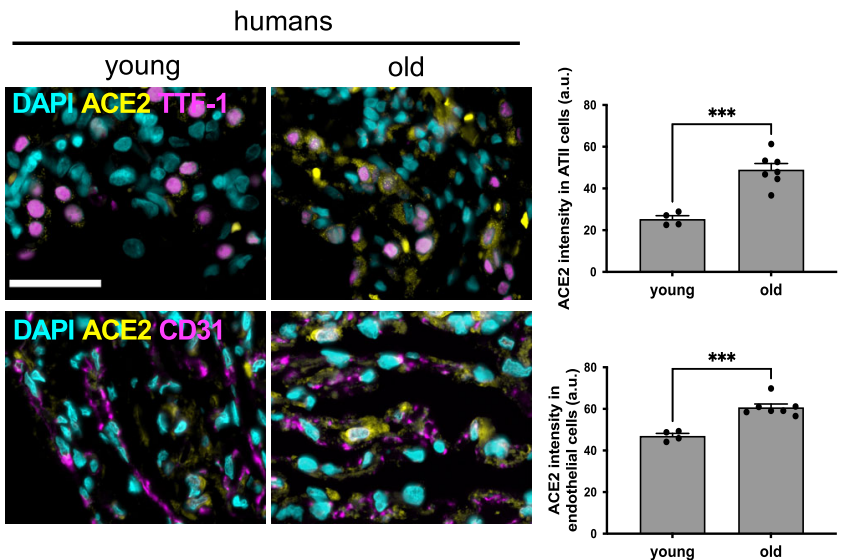

D

$\mathbf{F}$
B

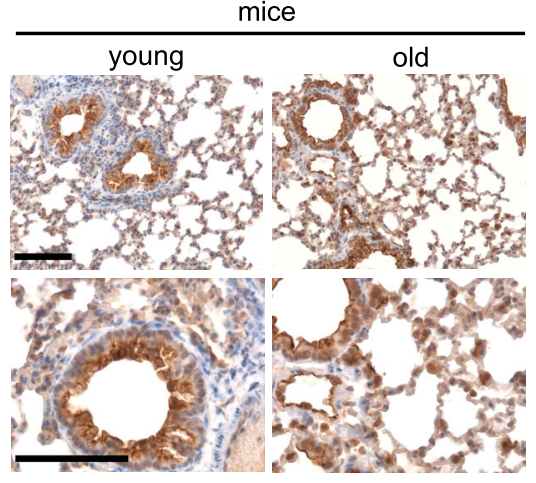

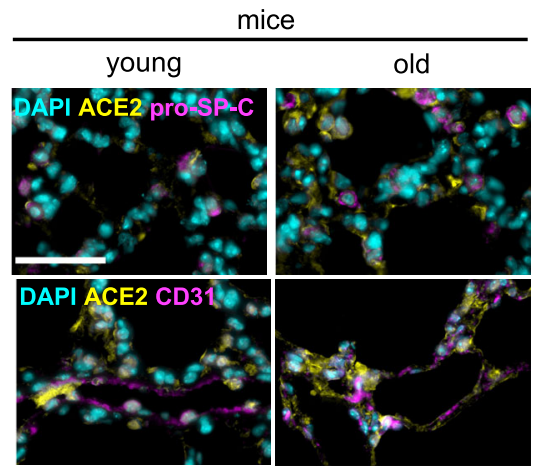
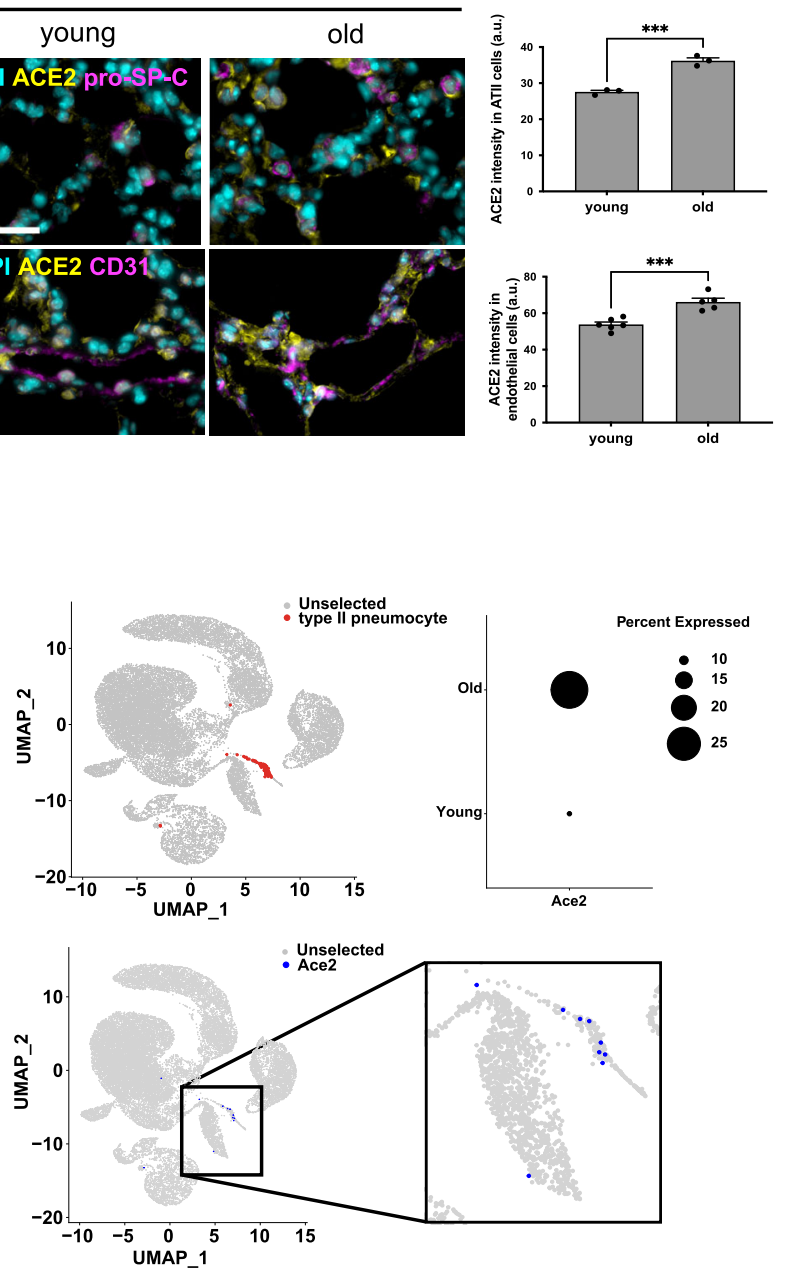

Figure 1.

We observed an increase in Ace2 mRNA levels (Fig 1A) in lungs of old mice (22-24 months) compared with young mice (2-3 months) as detected by RT-qPCR. Immunohistochemistry (IHC) of the same lungs confirmed and extended this observation to the ACE2 protein, which was detected in both pneumocytic and stromal/inflammatory elements in the lungs of old mice (Fig 1B). Quantitative analyses of IHC staining showed a significant increase in terms of signal density in old mice compared with young ones (Fig 1B).

Prompted by these observations in mice, we extended them to human lung tissue samples by comparing ACE2 immunostaining in 
histologically normal lung parenchyma of old (60-80 years old) and young (20-35 years old) subjects. ACE2 protein expression levels in old subjects were higher than that of young subjects, as shown and quantified in Fig 1C.

Emerging evidence can be interpreted to suggest that the severity of SARS-CoV-2 infection correlates with high rates of alveolar epithelial type II (ATII) cell infection (Yee et al, 2020). To confirm that ACE2 increase occurs in ATII cells, we performed doublemarker immunofluorescence for ACE2 and markers identifying ATII cells (pro-SP-C in mice or TTF-1 in humans) in lung samples at different ages. Immunofluorescence revealed that ACE2 expression in ATII pneumocytes increased with aging (Fig 1D and E), and a similar increase was observed in other cell types (Fig EV1A and B), including endothelial CD31-positive cells (Fig 1D and E). To further investigate the differential expression of Ace2 transcripts, we took advantage of the single-cell transcriptomic mouse atlas spanning different ages (Almanzar et al, 2020) and we focused on lung expression data. We observed that Ace2 showed an ATII pneumocytepreferential expression that increased upon aging, while the housekeeping gene Gapdh was widely expressed in almost all cell types and did not change at the analyzed ages (Figs $1 \mathrm{~F}$ and EV1C and D). These conclusions are consistent with similar analyses performed on non-human primates (Ziegler et al, 2020).

In order to unravel the molecular mechanism controlling the upregulation of ACE2 during aging, we took advantage of in vitro and in vivo models, which recapitulate some key aspects of aging. Aging is associated with telomere shortening and damage in several tissues (Fumagalli et al, 2012; Hewitt et al, 2012; Demanelis et al, 2020; Vaiserman \& Krasnienkov, 2021), and COVID-19 patients with short telomeres measured in leukocytes have been proposed to be at increased risk of death (Aviv, 2020). To test whether telomere shortening is sufficient to modulate ACE2 expression, we measured its mRNA levels in human fibroblasts (BJ) and human bronchial epithelial cells (HBECs) at different population doublings - both cell types lack telomere maintenance mechanisms and undergo progressive telomere shortening upon proliferation (Fig EV2A and B) (Huffman et al, 2000; Peters-Hall et al, 2018). Both late passage BJ and HBEC had increased levels of ACE2 mRNA, compared to cells at early passages (Fig 2A and B). Recently, a shorter human ACE2 splicing isoform has been described and proposed to be upregulated by interferon response upon infection by different viruses (but not SARS-CoV-2). Such shorter splice isoform lacks the extracellular domain used as viral binding site by SARS-CoV-2 (Blume et al, 2021). The use of isoform-specific primers in RT-qPCR allowed us to demonstrate that the long isoform was confirmed to increase with passage number, while the short one was expressed at lower levels and did not increase in late passages cells (Fig EV2C).

We next extended our studies to a mouse model lacking the RNA component of telomerase $\left(\mathrm{Terc}^{-/-}\right)$, which, at late generations, shows telomere shortening (Fig EV3A) and recapitulates several features of human aging in different tissues (Lee et al, 1998; Rudolph et al, 1999; Giorgio et al, 2016), including lungs (PiñeiroHermida et al, 2020). When we analyzed the expression level of ACE2 protein in the lungs of the third generation (G3) of $\mathrm{Terc}^{-/-}$ mice, we observed a consistent increase in ACE2 expression when compared to age- and sex-matched wild-type animals (Fig 2C). Immunofluorescence imaging with specific cell markers demonstrated that ACE2 increased mainly in ATII pneumocytes expressing
pro-SP-C (Fig 2D), with a significant increase also in pro-SP-Cnegative cells (Fig EV3B), although no significant difference was observed specifically in the endothelial cells (Fig 2D). The results obtained in vitro and in vivo clearly point to the role of telomeric shortening in the regulation of ACE2 levels in human cells and mouse tissues.

When telomeres become critically short, they activate the DNA damage response (DDR) pathway (d'Adda di Fagagna et al, 2003; Herbig et al, 2004). To test whether telomeric DDR is sufficient to increase ACE2 mRNA levels, we used two mammalian cell systems, which allow the activation of the DDR specifically at telomeres, in the absence of telomere shortening. TRF2, a component of the shelterin complex, prevents telomeric DNA from being recognized as DD and thus preventing the activation of DDR (Palm \& De Lange, 2008).

We used Trf2 conditional knockout mouse embryonic fibroblasts (MEFs $\operatorname{Trf}_{2}{ }^{\mathrm{F} / \mathrm{F}}$ ) carrying a Cre recombinase (Rosa26-CreERT2) inducible by 4-hydroxytamoxifen (4OHT) (Okamoto et al, 2013) and HeLa cells with a doxycycline-regulated expression of a short hairpin against TRF2 (HeLa shTRF2) to knockdown TRF2 expression (Grolimund et al, 2013).

TRF2 knockout or knockdown led to telomeric DDR activation as shown by increased levels of $\gamma \mathrm{H} 2 \mathrm{AX}$ foci and telomeric damageinduced long non-coding RNA (tdilncRNA) in both cell systems (Rossiello et al, 2017) (Figs 3A and C, and EV4A-D). In both models, DDR foci increase accompanied an increase in ACE2 mRNA levels (Fig 3B and D). Interestingly, DDR activation following ionizing radiation (IR) in the same cell lines (Fig EV5A and C) drove a similar increase in ACE2 mRNA levels (Fig EV5B and D), indicating that DDR signaling pathways mediate this response. To verify the effects of telomeric DDR in vivo, we next used an inducible Trf2 knockout mouse model ( $\operatorname{Tr} 2_{2}^{\mathrm{F} / \mathrm{F}}$ mice) (Rossiello et al, 2017) in which, following tamoxifen administration, Trf2 expression is lost, leading to DDR activation at telomeres as shown by the accumulation of foci of 53BP1 (Fig 3E). Parallel to DDR activation, we observed an increase in Ace2 mRNA levels in the liver upon tamoxifen administration (Fig $3 \mathrm{~F}$ ), demonstrating that also in vivo the activation of DDR at telomeres leads to increased Ace2 expression. Taken together, these results in human and mouse cell lines and in mouse tissues indicate a conserved role for the activated DDR pathways in modulating ACE2 levels. Since during physiological aging telomeric DDR accumulates, this likely contributes to the increased ACE2 levels.

One possibility is that the increase in ACE2 mRNA levels is caused by augmented activity of its transcriptional promoter. In order to determine whether the ACE2 promoter responds to DDR activation, we performed an in silico analysis to identify the transcription factors whose DNA-binding motifs are significantly enriched in the promoter region of $A C E 2$. Gene set enrichment analysis of the top 100 transcription factors (Table EV1) potentially associated with the ACE2 promoter revealed the presence of pathways related to the DNA damage response among the ones significantly enriched (Fig 4A) (Dicks et al, 2015; Karimaian et al, 2017; Wang et al, 2017; Mullenders, 2018).

To experimentally demonstrate that the ACE2 promoter responds to the activation of the DDR pathways, we transfected a plasmid carrying the luciferase reporter gene under the control of human ACE2 promoter in HeLa shTRF2 cells, and we induced telomeric DDR by TRF2 knockdown. Importantly, we observed an increase in 
A

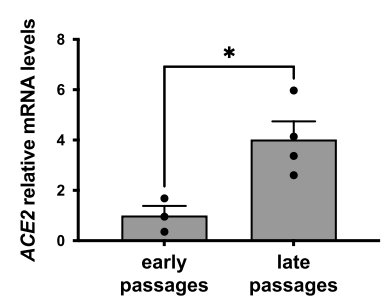

B

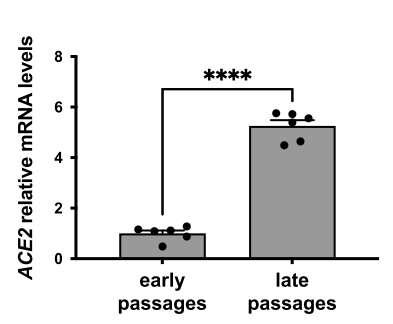

C

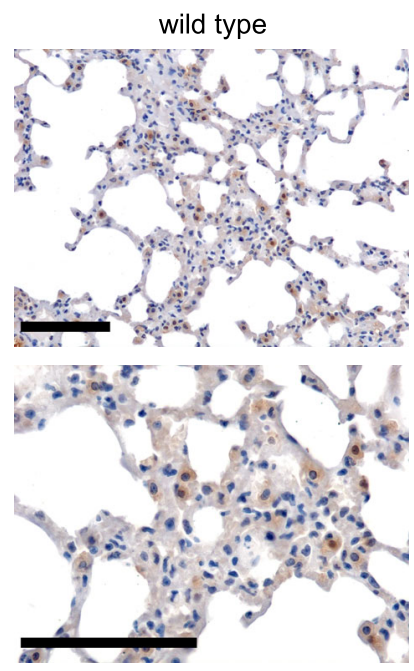

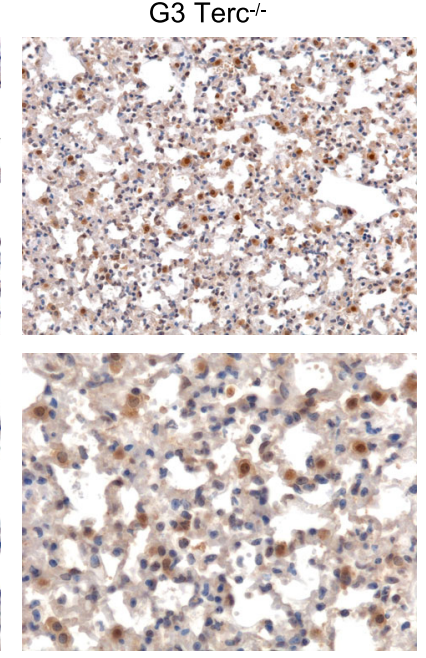

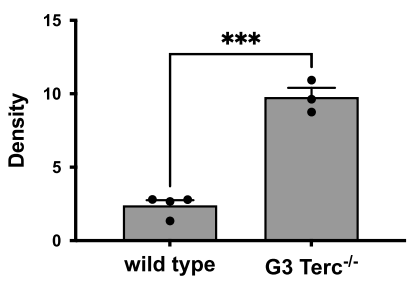

D

wild type
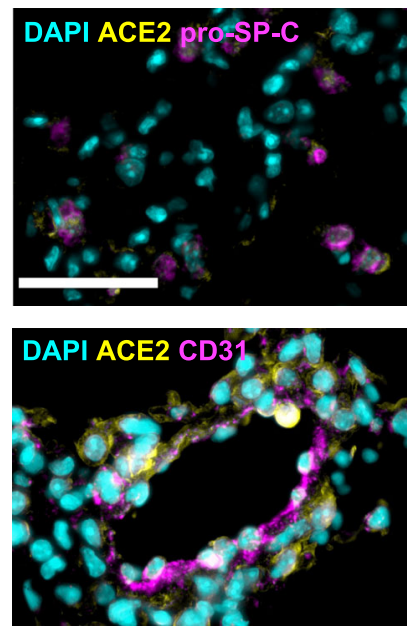

G3 Terc $^{-/-}$
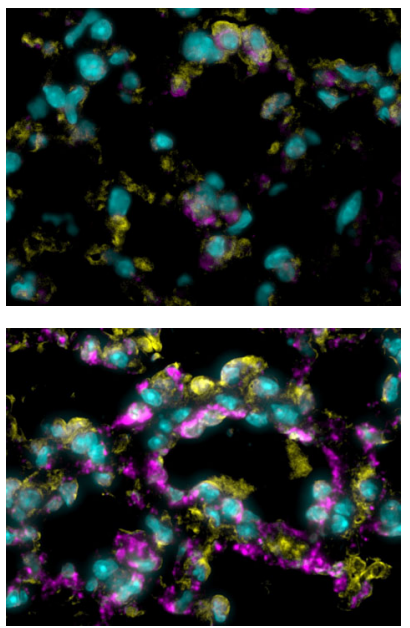
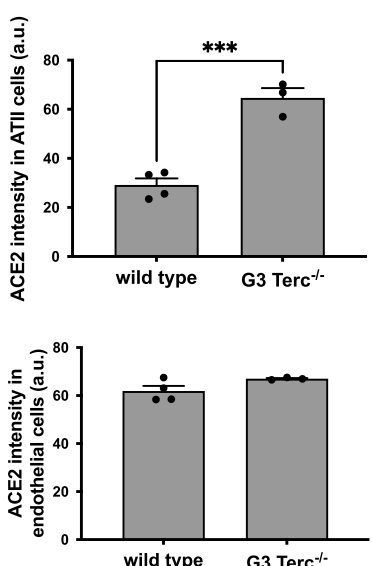

Figure 2. ACE2 levels increase upon telomere shortening in human cells and in lungs of G3 $\mathrm{Terc}^{-1-}$ mice.

A RT-qPCR detection of ACE2 mRNA expression levels in early passages (PD 34-37) and late passages (PD 61-64) human normal fibroblasts (BJ) ( $n=3-4$ replicates per group).

B ddPCR detection of ACE2 mRNA expression levels in early passages (PD 22.37) and late passages (PD 140) human bronchial epithelial cells (HBEC) ( $n=6$ replicates per group).

C Representative images and quantitative analyses of ACE2 immunohistochemical staining in lungs of age-matched wild-type and C3 Terc ${ }^{-1-}$ mice $(n=3-4$ mice per group). Scale bar, $200 \mu \mathrm{m}$.

D Double-marker immunofluorescence and quantitative analyses of ACE2 intensity level in pro-SP-C-positive type II pneumocytic and CD31-positive endothelia in lungs of age-matched wild-type and G3 Terc $^{-l-}$ mice $(n=3-4$ mice per group). Scale bar, $100 \mu \mathrm{m}$. a.u. = arbitrary units.

Data information: In (A-D), data are presented as mean \pm SEM. ${ }^{*} P<0.05,{ }^{* \star *} P<0.001,{ }^{* * *} P<0.0001$. Two-sided unpaired Student's $t$-test. 
A

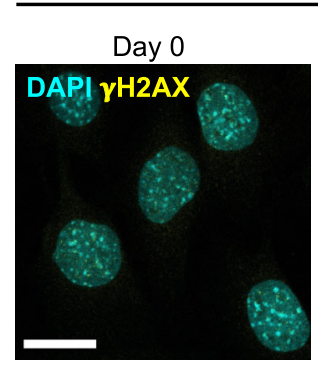

C

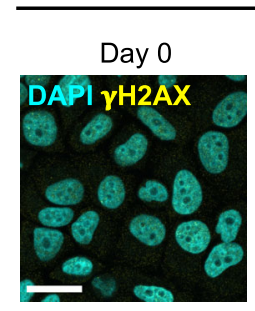

HeLa shTRF2
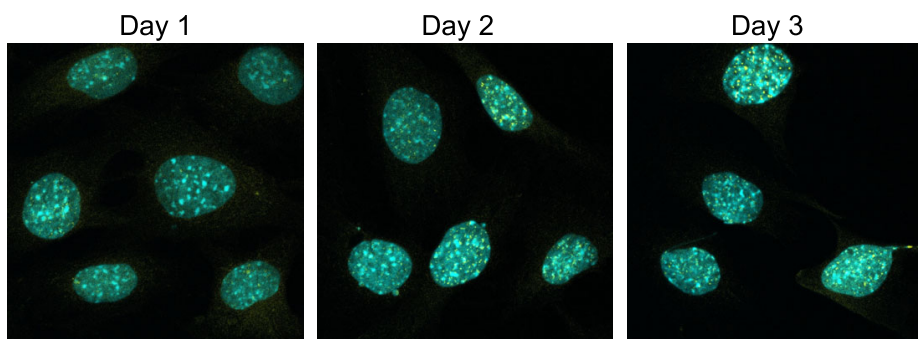

B

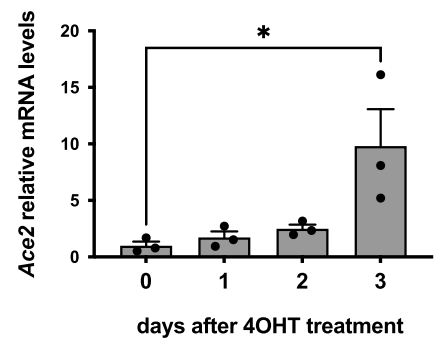

D

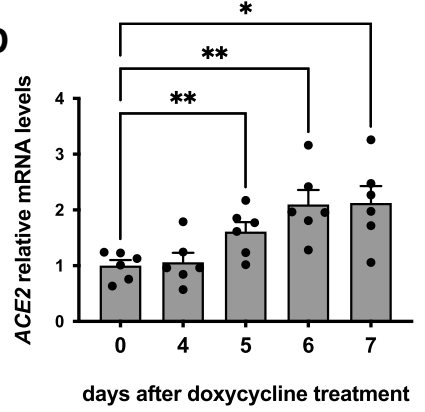

Day 6

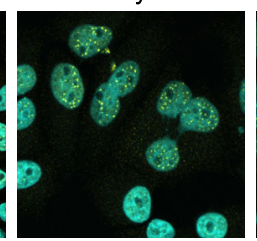

Day 7

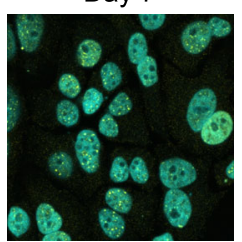

E

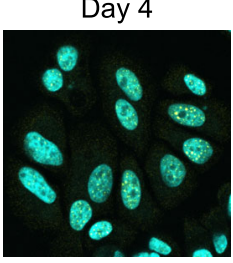

$\mathbf{F}$

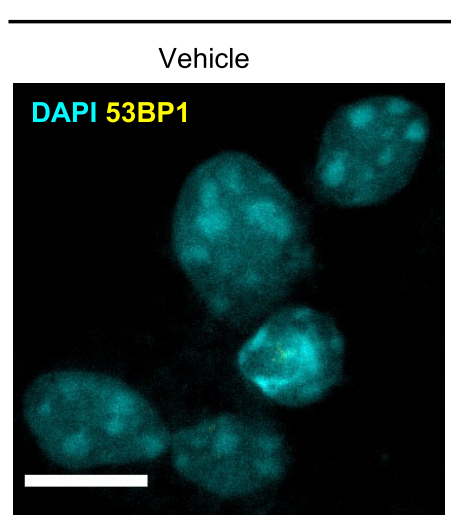

Trf2F/F mice

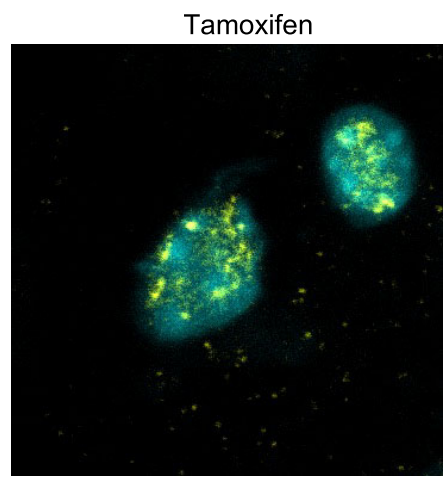

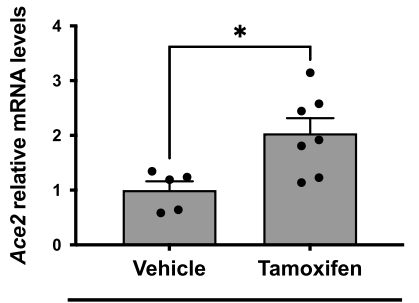

Trf2F/F mice

Figure 3. DDR activation induces ACE2 expression in cultured cells and in vivo.

A Immunofluorescence showing $\gamma \mathrm{H} 2 \mathrm{AX}$ foci in MEFs Trf2 ${ }^{\mathrm{F} / \mathrm{F}}$ at the indicated time points following $40 \mathrm{OTT}$ treatment and consequent TRF2 knockout. Scale bar, $25 \mu \mathrm{m}$.

B RT-qPCR detection of Ace 2 mRNA expression levels in MEFs Trf2 ${ }^{\mathrm{F} / \mathrm{F}}$ treated as in A ( $n=3$ independent experiments).

C Immunofluorescence showing $\gamma \mathrm{H} 2 \mathrm{AX}$ foci in HeLa shTRF2 cells at the indicated time points following doxycycline treatment and consequent TRF2 knockdown. Scale bar, $25 \mu \mathrm{m}$

D RT-qPCR detection of ACE2 mRNA expression levels in HeLa shTRF2 cells treated as in C ( $n=6$ independent experiments).

E Representative immunofluorescence images of 53BP1 staining in liver from Trf2 ${ }^{\mathrm{F} / \mathrm{F}}$ mice treated with tamoxifen (to induce TRF2 loss and telomere uncapping) or vehicle. The animals have been injected also with PBS. Scale bar, $10 \mu \mathrm{m}$.

F RT-qPCR detection of Ace 2 mRNA expression levels in livers of mice treated as in $E$ ( $n=5-7$ mice per group).

Data information: In (B, D, F), data are presented as mean \pm SEM. ${ }^{*} P<0.05$, ${ }^{*} P<0.01$. Two-sided unpaired Student's $t$-test (F) or two-way paired ANOVA (B, D).

luciferase signal upon telomere dysfunction (Fig 4B). Since a similar transcriptional activation was observed also upon DDR activation in irradiated uninduced HeLa cells, this indicates that DDR pathway engagement controls ACE2 promoter activity (Fig 4B).

To further demonstrate that key components of DDR pathways are responsible for the observed increase in Ace2 mRNA levels, we treated MEFs $\operatorname{Trf}^{\mathrm{F} / \mathrm{F}}$ with the ATM kinase inhibitor KU-60019 (ATMi) when inducing Trf2 knockout by 4 OHT treatment or generating DSBs by IR. While this treatment prevented DDR foci formation as expected (Figs 5A and EV5E), it also significantly reduced Ace2 mRNA level increase (Figs 5B and EV5F), demonstrating ATM kinase activity involvement in the regulation of Ace 2 transcript levels. 


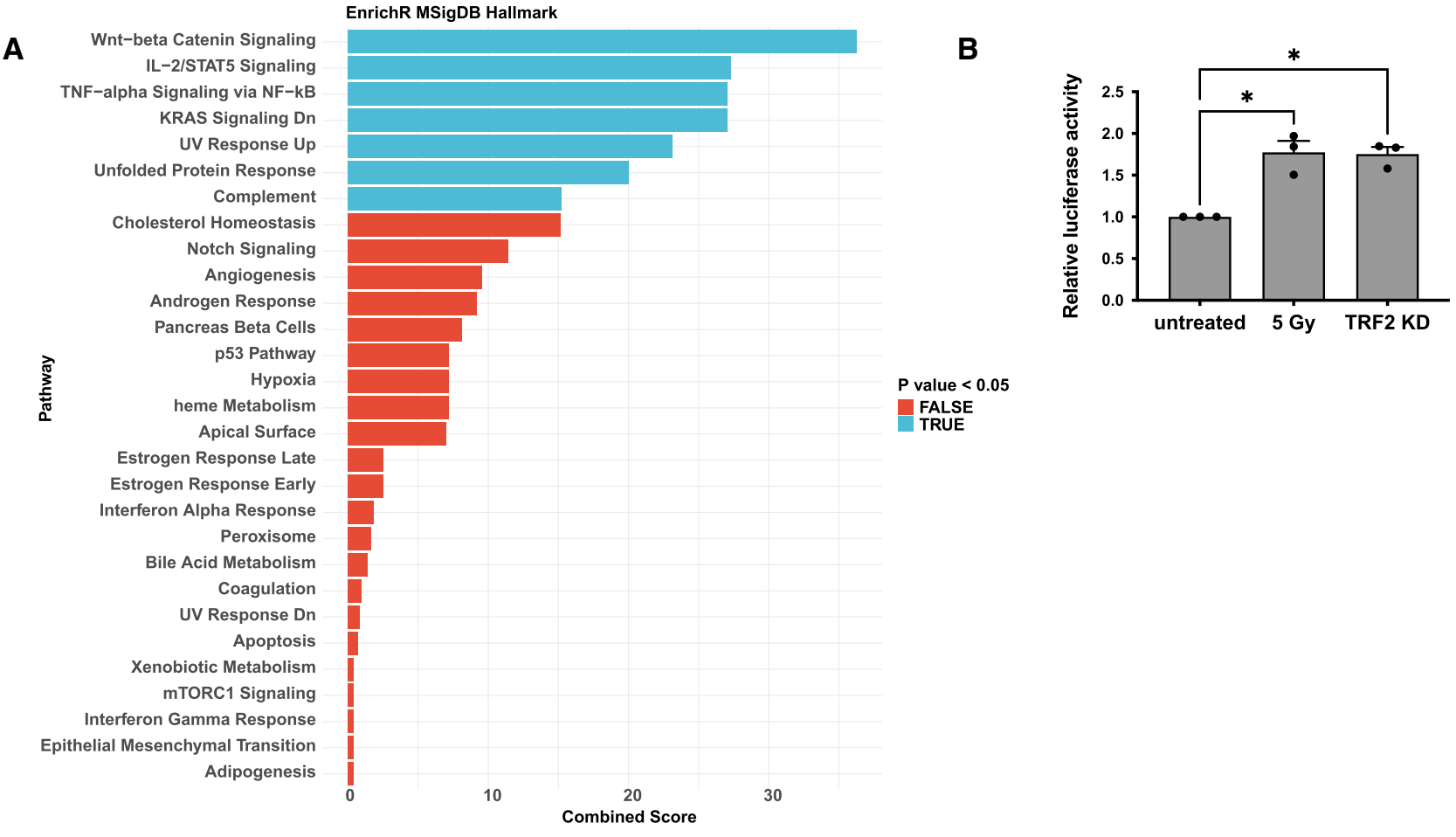

Figure 4. DDR activation mediates transcriptional upregulation of ACE2 gene.

A Gene set enrichment analysis showing enriched pathways from the MSigDB_Hallmark gene set library. Bars are colored according to $P$-value, with significantly enriched pathways $(P<0.05)$ in blue. Combined score: combined value of both the $P$-value and $z$-score.

B Relative luciferase activity in HeLa shTRF2 following ionizing radiation (5 Gy) or TRF2 knockdown upon doxycycline-induced shTRF2 expression ( $n=3$ independent experiments). Error bars represent the SEM. ${ }^{\star} P<0.05$. Two-way paired ANOVA.

In order to investigate whether inhibition of telomeric DDR affects the expression of ACE2 also in vivo, we took advantage of telomeric antisense oligonucleotides (tASOs), which allow the specific inhibition of telomeric DDR by targeting tncRNA generated at dysfunctional telomeres and necessary for full DDR activation at telomeres (Michelini et al, 2017; Rossiello et al, 2017; Aguado et al, 2019). To test the impact of selective telomeric DDR inhibition on ACE2 expression following tamoxifen-induced $\operatorname{Tr} 2$ loss, mice were treated with a systemic dose of anti-teloG or anti-teloC tASOs, or phosphate-buffered saline (PBS) as negative control, delivered by intraperitoneal injection. Four days later, when telomeric DDR reached the maximal activation in this model, mice were sacrificed and tissues analyzed. Both tASO treatments were highly effective, as demonstrated by decreased numbers of 53BP1 foci (Fig 5C, Rossiello et al, 2017), that correlate with the downregulation of Ace2 mRNA levels in vivo (Fig 5D).

Stimulated by this result, we extended our studies to the G3 $\mathrm{Terc}^{-/-}$mouse model. We treated 3-month-old G3 $\mathrm{Terc}^{-/-}$mice with anti-teloG or anti-teloC tASOs or an ASO with an unrelated sequence (Control) by intraperitoneal injection, and we sacrificed them at 12 months of age. Quantitative IHC analyses of ACE2 expression in lungs revealed high levels of the protein in control G3 $\mathrm{Terc}^{-/-}$mice, compared to age- and sex-matched wild-type animals. Such an expression was significantly reduced by the treatment with either tASOs (Fig 5E), and this occurred also in pro-SP-C-positive
ATII cells, as shown by double-marker immunostaining (Fig 5F). These results also support the notion that it is the ensuing DDR activation, rather than telomeric shortening per se, that is responsible for ACE2 regulation.

Taken together, these results demonstrate that the expression of ACE2, the SARS-CoV-2 receptor, is directly modulated by the activation of the DDR pathway at the transcriptional level and that telomere dysfunction is a physiological event able to engage the DDR pathways modulating ACE2 levels.

ACE2 is a potent negative regulator of the renin-angiotensin system (RAS), which maintains the homeostasis of blood pressure and the balance of fluid and salts (Patel et al, 2017). The homeostasis of RAS is critical for the physiological and pathological regulation in various organs, including the heart, kidneys, and lungs (Patel et al, 2017). ACE2 can degrade angiotensin (Ang) II, which causes vasoconstriction, inflammation, and fibrosis, and converts it into Ang (1-7), which leads to vasodilation, reduced proliferation, and apoptosis, suggesting that its increase might represent a mechanism to counteract the molecular changes related to aging (Hamming et al, 2007). Although the ACE2 increase in physiological conditions may have positive homeostatic effects, being also the SARS-CoV-2 receptor, it favors infectability, thus causing more severe symptoms in the elderly.

The evidence that blocking the interaction between SARS-CoV-2 $S$ protein and ACE2 (Monteil et al, 2020) or modulating ACE2 level 
by different means, including androgen receptor and BET inhibitors (Qiao et al, 2021), can in turn regulate the SARS-CoV-2 cell entry suggests that reducing ACE2 expression can have a beneficial effect on COVID-19 infection rates and on the severity of symptoms.

Here, we have shown that another pathway, the DDR, can be targeted to reduce ACE2 expression and that tASOs are agents effective in controlling ACE2 levels in vivo in mouse tissues, including the lung. In perspective, as ASOs are established medicines approved for a number of disorders (Crooke et al, 2021) and as telomeric DDR increases with age in normal and pathological conditions (Chakravarti et al, 2021) (Rossiello et al, Nature Cell Biology, in press), we suggest that, upon additional validation,
A
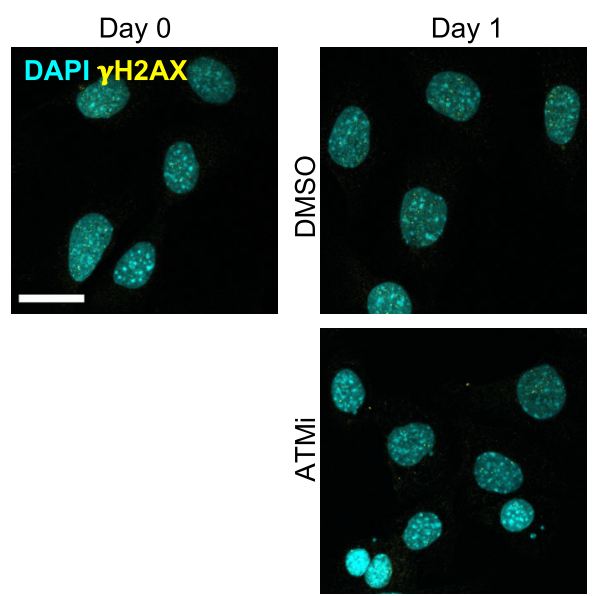

Day 3

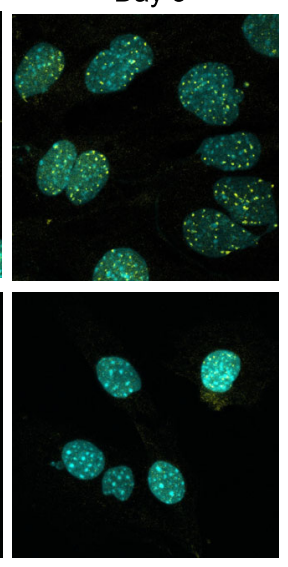

C

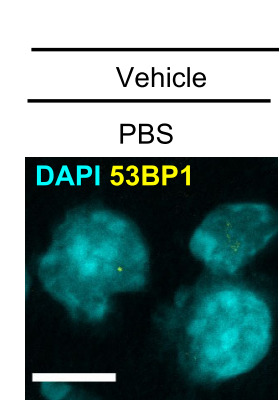

Trf2 F/F mice

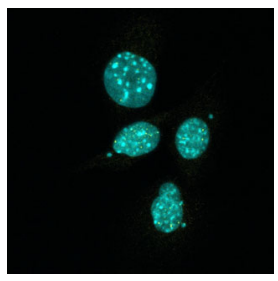

B
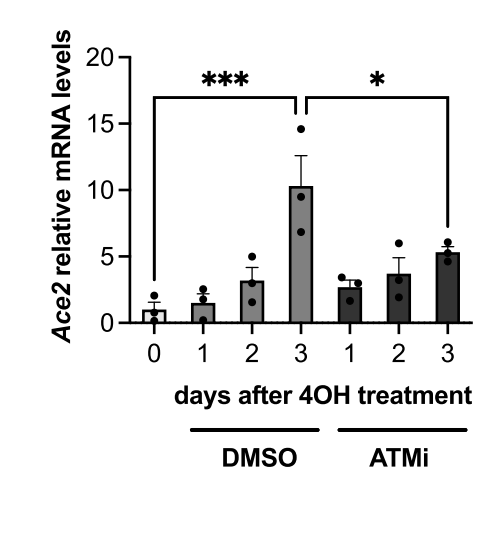

D

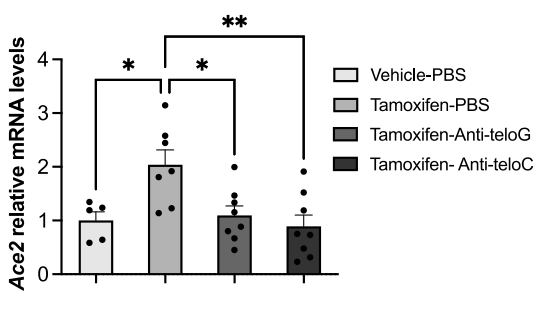

E

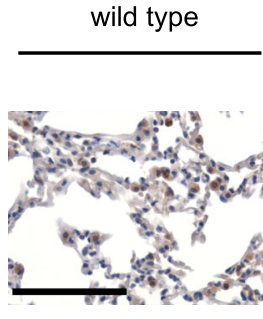

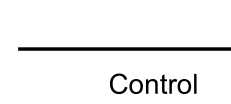

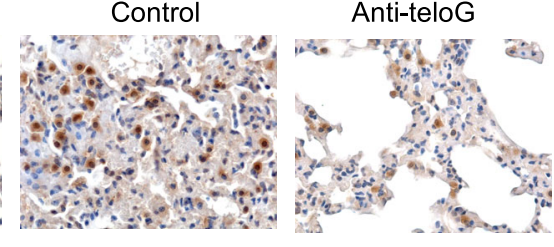

Anti-teloC

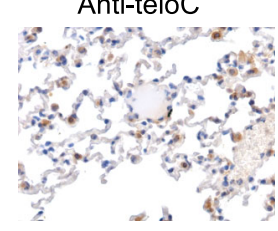

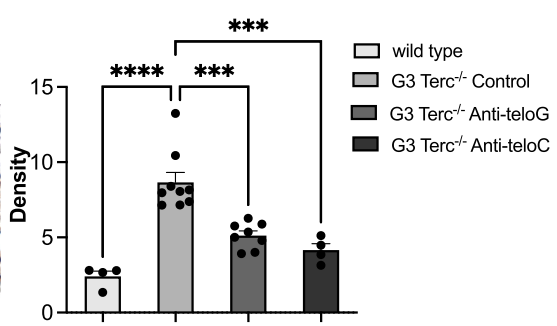

$\mathbf{F}$

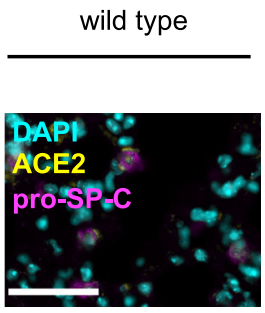

G3 Terc $^{-1}$
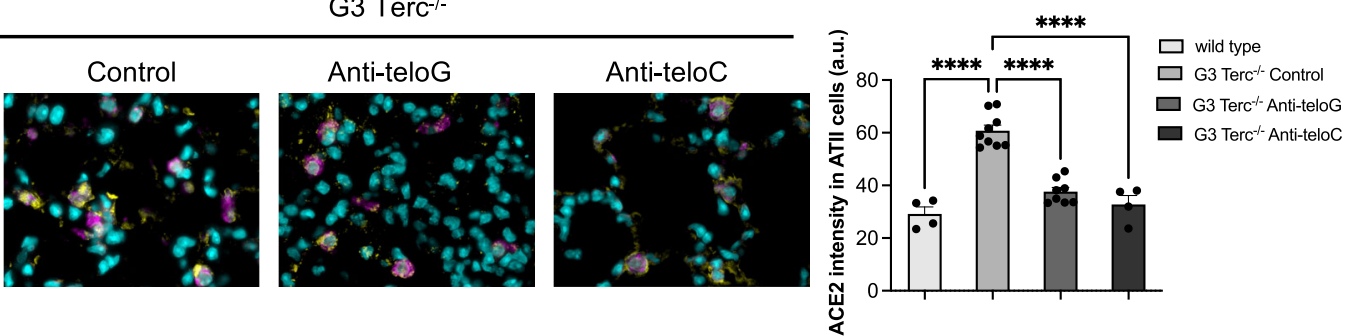

Figure 5. 
Figure 5. Selective inhibition of telomeric DDR decreases ACE2 expression in cultured cells and in vivo.

A Immunofluorescence showing $\gamma \mathrm{H} 2 \mathrm{AX}$ foci in $\mathrm{Trf}^{\mathrm{F} / \mathrm{F}} \mathrm{MEFs}$ at the indicated time points following $4 \mathrm{OHT}$ treatment and consequent TRF2 knockout and treated with DMSO or ATMi. Scale bar, $25 \mu \mathrm{m}$.

B RT-qPCR detection of Ace2 mRNA expression levels in MEFs Trf2 ${ }^{\mathrm{F} / \mathrm{F}}$ treated as in A ( $n=3$ independent experiments).

C Representative immunofluorescence images of 53BP1 staining in liver from Trf2 ${ }^{\mathrm{F} / \mathrm{F}}$ mice treated with tamoxifen (to induce telomere uncapping) or vehicle and injected with the indicated ASOs or PBS as control. Scale bar, $10 \mu \mathrm{m}$.

D RT-qPCR detection of Ace2 mRNA levels in livers of mice treated as in C ( $n=5-8$ mice per group).

E Representative microphotographs and quantitative analyses of ACE2 immunohistochemical staining in lungs of age-matched wild-type and G3 Terc ${ }^{-1-}$ mice, treated with the indicated ASOs ( $n=4-9$ mice per group). Scale bar, $200 \mu \mathrm{m}$.

F Double-marker immunofluorescence and quantitative analyses of ACE2 intensity level in pro-SP-C-positive type II pneumocytic cells in lungs of age-matched wildtype and $\mathrm{G} 3 \mathrm{Terc}^{-1-}$ mice, treated with the indicated ASOs $(n=4-9$ mice per group). Scale bar, $100 \mu \mathrm{m}$. a.u. $=$ arbitrary units.

Data information: In (B, D-F), data are presented as mean \pm SEM. ${ }^{*} P<0.05,{ }^{* \star} P<0.01,{ }^{* \star *} P<0.001,{ }^{* \star \star} P<0.0001$. Two-way paired (B) or unpaired (D-F) ANOVA.

tASOs have a potential as therapeutic agents to reduce susceptibility to COVID-19.

Our evidence that DDR controls ACE2 levels in different organs and in cells of different species and origin suggests that this mechanism is conserved across species and cell types. Since ACE2 is normally expressed also outside the lungs (such as intestine, liver, kidney, testicles, placenta and others), our observations may have a broader impact, beyond COVID-19. Furthermore, our findings may be relevant also for all those conditions associated with increased DDR, such as those characterized by chronic inflammation, or cancer patients undergoing chemotherapy or radiotherapy.

\section{Materials and Methods}

\section{Cells and treatments}

Foreskin fibroblast BJ cells (The American Type Culture Collection) were grown in MEM supplemented with $10 \%$ fetal bovine serum, $1 \%$ glutamine, $10 \mathrm{mM}$ non-essential amino acids, and $1 \mathrm{mM}$ sodium pyruvate.

Primary human bronchial epithelial cells (HBECs) were cocultured with irradiated 3T3 J2 feeder cells with ROCK inhibitor and $2 \% \mathrm{O}_{2}$ (ROCKi conditions) as described previously (Peters-Hall et al, 2018).

MEFs Rosa26-CreERT2 $\operatorname{Trf}^{\mathrm{F} / \mathrm{F}}$ (Okamoto et al, 2013), a kind gift from Eros Lazzerini Denchi (National Cancer Institute, NIH, Bethesda, USA), were grown in DMEM supplemented with $10 \%$ fetal bovine serum and $1 \%$ glutamine; for CreER activation, cells were treated with 600 nM 4-hydroxytamoxifen (4OHT, H7904, Sigma-Aldrich).

HeLa-inducible shTRF2 cells (Grolimund et al, 2013), a kind gift from Joachim Lingner (ISREC-EPFL, Lausanne, Switzerland), expressing the tTR-KRAB construct, the dsRED marker and the doxycycline-inducible shTRF2 and GFP marker, were grown in DMEM supplemented with $10 \%$ Tet system-approved fetal bovine serum and $1 \%$ glutamine; for shTRF2 and GFP induction, cells were treated with doxycycline $(1 \mu \mathrm{g} / \mathrm{ml})$.

All cell lines used in this study were grown under standard cell culture conditions $\left(37^{\circ} \mathrm{C}, 5 \% \mathrm{CO}_{2}\right)$ and were tested negative for mycoplasma contaminations.

Ionizing radiation was induced by a high-voltage X-ray-generator tube (Faxitron X-Ray Corporation).

ATM kinase inhibitor KU-60019 (S1570 Selleckchem), or dimethyl sulfoxide as negative control, was used at $10 \mu \mathrm{M}$ concentration.

\section{Animals and treatments}

Experiments involving animals have been done in accordance with the Italian Laws (D.lgs. 26/2014), which enforce Directive 2010/63/ EU (Directive 2010/63/EU of the European Parliament and of the Council of 22 September 2010 on the protection of animals used for scientific purposes). Accordingly, the project has been authorized by the Italian Competent Authority (Ministry of Health).

For the analysis of young and old mice, C57BL/6J mice (females and males) were purchased from the Charles River Laboratories. Young animals were sacrificed at 2-3 months of age, while old animals at 22-24 months of age. After collection, lungs were snapfrozen for RNA extraction and formalin-fixed and paraffinembedded for histological analysis.

Terc $^{+/-}$mice (B6. Cg-Terctm1Rdp/J Stock No: $004132 \mid \mathrm{mTR}^{-/-}$) (Blasco et al, 1997) were purchased by Jackson Laboratory. Terc ${ }^{+/-}$ mice were intercrossed to generate first-generation (G1) homozygous $\mathrm{Terc}^{-/-}$knockout mice. Second-generation (G2) $\mathrm{Terc}^{-1-}$ mice were generated by successive breeding of G1 $\mathrm{Terc}^{-/-}$and then G3 $\mathrm{Terc}^{-/-}$ mice by crosses between G2 $\mathrm{Terc}^{-/-}$mice. Finally, wild-type C57BL/ $6 \mathrm{~J}$ and G3 $\mathrm{Tert}^{-1-}$ mice were used for the experiments. The 8- to 10week-old mice were injected intraperitoneally (i.p.) with a control, anti-teloG, and anti-teloC ASO at a final concentration of $15 \mathrm{mg} / \mathrm{kg}$ twice a week for 4 weeks. The animals were sacrificed at 12 months of age. The lungs were collected, and part of it was snap-frozen for RNA extraction and part was washed in PBS and collected for fixation in $10 \%$ neutral-buffered formalin overnight, washed in water, and paraffin-embedded for histological analysis.

Rosa26-CreERT mice (Jackson Laboratory) and TRF2 conditional knockout mice (Celli \& de Lange, 2005) and mice carrying a p53 conditional allele (Jackson Laboratory) were crossed to generate Trf2/p53/Rosa26 mice. Mice were maintained in 129/c57Bl6 genetic background. Mice were bred and maintained under pathogen-free condition at the Scripps Research Institute and were handled according to Institutional Animal Care and Use Committee guidelines. The animals were provided by Eros Lazzerini Denchi (National Cancer Institute, NIH, Bethesda, USA). To activate CreER, 8- to 10-week-old mice were injected intraperitoneally (i.p.) with tamoxifen dissolved in sunflower oil or with vehicle at a final concentration of $75 \mathrm{mg} / \mathrm{kg}$. After 24 h vehicle (PBS), anti-teloG and anti-teloC ASO dissolved in PBS were administrated by i.p. injection at a concentration of $15 \mathrm{mg} / \mathrm{kg}$. Mice were sacrificed after 5 days post-tamoxifen injection. Tissues were collected and frozen in dry ice and embedded in OCT tissue TEC (Sakura). 


\section{Human samples}

Human lung tissue samples were collected from the archives of the Department of Clinical and Molecular Medicine, Pathology Unit, Sant'Andrea Hospital, Sapienza University, Rome, Italy. Samples were relative to histologically normal parenchyma adjacent to either foci of subpleural emphysema (young subjects) or non-small-cell lung cancer (old subjects). The samples were collected and handled according to the Helsinki Declaration. Patients provided written informed consent to the use of their tissue samples for research purposes (Ethical Approval SA250).

\section{Antisense oligonucleotides (ASOs) sequences}

The locked nucleic acid-modified oligonucleotides with a fully phosphorothioate backbone were produced by Qiagen as described (Rossiello et al, 2017).

Sequences were as follows $\left(5^{\prime}-3^{\prime}\right.$ orientation):

control: ACTGATAGGGAGTGGTAAACT.

anti-teloG: CCCTAACCCTAACCCTAACCC.

anti-teloC: GGGTTAGGGTTAGGGTTAGGG.

\section{Immunolocalization and quantitative analyses for mouse and human paraffin-embedded tissues}

Four-micrometer-thick human and mouse tissue sections were deparaffinized, rehydrated, and unmasked using Novocastra Epitope Retrieval Solutions pH8 in thermostatic bath at $98^{\circ} \mathrm{C}$ for $30 \mathrm{~min}$. Subsequently, the sections were brought to room temperature and washed in PBS. After neutralization of the endogenous peroxidase with $3 \% \mathrm{H}_{2} \mathrm{O}_{2}$ and $\mathrm{Fc}$ blocking by a specific protein block (Leica Novocastra), the samples were incubated with the primary antibodies.

IHC staining was revealed using Novolink Polymer Detection Systems (Leica Novocastra) or IgG (H\&L)-specific secondary antibodies (Life Technologies, 1:500) and DAB (3,3'-diaminobenzidine, Leica Novocastra) as substrate chromogen.

For multiple-marker immunostainings, sections were incubated with ACE2 and TTF-1 primary antibodies and the binding of the primary antibodies to their respective antigenic substrates was revealed by made-specific secondary antibodies conjugated with Alexa-488 (Life Technologies, 1:250) and Alexa-568 (Life Technologies, 1:300) fluorochromes. In order to multiplex antibodies raised in the same species (ACE2 and pro-SP-C or CD31), Opal Multiplex IHC kit was developed. After deparaffinization, antigen retrieval in pH8 buffer was brought to a boil at $100 \%$ power, followed by $20 \%$ power for 15 min using microwave technology (MWT). Sections were treated with blocking buffer for $10 \mathrm{~min}$ at room temperature before primary antibody incubation. Slides were then incubated with polymeric horseradish peroxidase-conjugated (HRP) secondary antibody for $10 \mathrm{~min}$, and the signal was visualized using Opal 520 fluorophore-conjugated tyramide signal amplification (TSA) at 1:100 dilution. The HRP catalyzes covalent deposition of fluorophores around the marker of interest. The slides were again processed with the microwave treatment to strip primary/secondary antibody complex and allow the next antigen-antibody staining. Another round of staining was performed with the second primary antibody incubation, followed by Polymeric horseradish peroxidase- conjugated (HRP) secondary antibody and Opal 620 fluorophoreconjugated tyramide signal amplification (TSA) at 1:100 dilution for signal visualization. Finally, slides were again microwaved in antigen retrieval buffer and nuclei were subsequently visualized with DAPI (4',6-diamidino-2-fenilindole).

Slides were analyzed under a Zeiss Axioscope A1 microscope equipped with four fluorescence channels widefield IF. Microphotographs were collected using a Zeiss Axiocam 503 Color digital camera with the Zen 2.0 Software (Zeiss).

Quantitative analyses of ACE2 immunohistochemical stainings were performed by calculating the average percentage of positive signals in five non-overlapping fields at medium-power magnification $(\times 200)$ using the Positive Pixel Count v9 Leica Software Image Analysis. Multiple-marker immunofluorescence stainings were analyzed through the use of the segmentation-based algorithm "HighPlex FL v4.13" of HALO software (Indica Labs), quantifying the intensity of ACE2 expression in type II pneumocytic pro-SP-C- or TTF-1-positive cells. For endothelial cell ACE2 quantitative analyses, the area quantification algorithm "Area Quantification FL v2.1.7" of the HALO software was adopted, which allowed scoring of ACE2 signal intensity in the CD31-positive endothelial lining independently of cell segmentation.

\section{Immunofluorescence for OCT-embedded mouse tissues}

A measure of 4 -mm tissue sections was fixed for $10 \mathrm{~min}$ in $4 \%$ paraformaldehyde (PFA) and incubated in blocking solution $(2 \%$ BSA, $0.1 \%$ Tween in PBS) for $1 \mathrm{~h}$ at RT. Then, sections were incubated for $1 \mathrm{~h}$ at RT with primary antibodies, washed in blocking solution, and incubated for $1 \mathrm{~h}$ at RT with secondary antibody. Nuclei were stained with 4,6-diamidino-2-phenylindole (DAPI; 1 $\mathrm{mg} / \mathrm{ml}$ ). Samples were mounted with glycerol solution. Image acquisition was performed in a Leica TCS SP5 confocal microscope. The detection parameters were set in the control samples and were kept constant across specimens.

\section{Immunofluorescence for cultured cells}

Cells were fixed with 4\% PFA. After incubation with blocking solution, cells were stained with primary antibody for $1 \mathrm{~h}$ at RT, washed, and incubated with secondary antibodies for $40 \mathrm{~min}$ at RT. Nuclei were stained with DAPI $(1 \mathrm{mg} / \mathrm{ml})$. Samples were mounted in mowiol. Image acquisition was performed in a Leica AOBS SP2 confocal microscope. The detection parameters were set in the control samples and were kept constant across specimens. The quantification of the number of DDR foci per cell was performed in a semi-quantitative manner by CellProfiler software.

\section{FISH for cultured cells and mouse tissues}

Cells were fixed with $4 \%$ PFA. Mouse lungs were fixed with $4 \%$ PFA and cryoprotected with Sucrose $30 \%$ before freezing. Fixed cells and 7-mm tissue sections were permeabilized with triton $0.1 \%$ for $20 \mathrm{~min}$ RT, incubated with glycine $10 \mathrm{mM}$ for $30 \mathrm{~min}$ RT, washed, denatured at $80^{\circ} \mathrm{C}$ for $5 \mathrm{~min}$, and incubated with Cy5conjugated TelC PNA probe (F1003-Panagene). After washes, nuclei were stained with 4,6-diamidino-2-phenylindole (DAPI; 1 $\mathrm{mg} / \mathrm{ml}$ ). Lung slide was mounted with VECTASHIELD ${ }^{\circledR}$ Antifade 
Mounting Medium (H-1000-10), and cells were mounted with mowiol. Image acquisition was performed in a Leica TCS SP5 confocal microscope. The detection parameters were set in the control samples and were kept constant across specimens. The quantification of the signal was performed in a semi-quantitative manner by CellProfiler software.

\section{Antibodies}

The following primary antibodies were adopted for IHC and IF on mouse and human samples: rabbit polyclonal ACE2 (1:500 pH8, ab15348, Abcam), rabbit polyclonal Prosurfactant Protein C (1:200 pH9, AB3786, Merck Millipore), mouse monoclonal TTF-1 (clone SPT24, 1:100 pH6, NCL-L-TTF-1, Leica Novocastra), rabbit polyclonal anti CD31 (1:50 pH9, ab28364, Abcam), rabbit polyclonal anti-53BP1 (1:1,000, sc-22760, Santa Cruz), and mouse monoclonal anti-phospho-Histone H2A.X (1:500, 05-636, Sigma-Aldrich).

\section{Telomere Shortest Length Assay (TeSLA)}

Genomic DNA was extracted using the Gentra Puregene DNA Extraction Kit (Qiagen) according to the manufacturer's instructions and quantified on a NanoDrop (Thermo Scientific). TeSLA measurements were performed as previously described (Lai et al, 2017). In brief, T4 DNA ligase (New England Biolabs), 1 mM ATP, $10-3 \mu \mathrm{M}$ of TeSLA-Ts, and $50 \mathrm{ng}$ of isolated genomic DNA were mixed in $1 \times$ CutSmart buffer (New England Biolabs) and incubated at $35^{\circ} \mathrm{C}$ for $12-16 \mathrm{~h}$. The mixture was then digested with CviAII, BfaI, NdeI, and MseI (New England Biolabs) to generate DNA fragments with 5' AT and TA overhangs. Shrimp alkaline phosphatase (rSAP; New England Biolabs) was added to the digested mixture to remove $5^{\prime}$ phosphate from each DNA fragment. The mixture was combined with T4 DNA ligase, $1 \mathrm{mM}$ ATP, $1 \mu \mathrm{M}$ of AT adapter, and $1 \mu \mathrm{M}$ of TA adapter in $1 \times$ CutSmart buffer to incubate at $16^{\circ} \mathrm{C}$ for $12-16 \mathrm{~h}$. Multiple PCRs were then performed using FailSafe Enzyme Mix (Lucigen) with $1 \times$ FailSafe buffer $\mathrm{H}$ containing 0.25 $\mu \mathrm{M}$ AP/TeSLA-TP primers and $40 \mathrm{pg}$ of ligated DNA. PCR products were resolved on a $0.85 \%$ agarose gel $(1.5 \mathrm{~V} / \mathrm{cm}$ for $19 \mathrm{~h})$. After gel electrophoresis, Southern blot is applied to detect amplified telomeres.

\section{RNA extraction from mouse tissues}

To isolate RNA, 20-30 mg lung tissue was homogenized in TRIzol (Life Technologies) with Tissue Lyzer II (Qiagen) and processed with RNeasy Kit (Qiagen) according to the manufacturer's specifications. To increase the purity of the RNA extracted, a convenient on-column DNase (Qiagen) treatment was performed to remove the residual amounts of DNA. NanoDrop spectrophotometer was used to detect RNA quantity and purity. RNA purity was ascertained via NanoDrop 260/280 and 260/230 ratios.

\section{RNA extraction from cultured cells}

For MEFs, HeLa, and BJ cells, total RNA was extracted using Maxwell ${ }^{\circledR}$ RSC Instrument, with Maxwell ${ }^{\circledR}$ RSC simplyRNA Tissue Kit (AS134, Promega), following manufacturer's instructions. NanoVue $^{\mathrm{TM}}$ Plus Spectrophotometer (GE Healthcare) was used to detect
RNA quantity and purity. RNA purity was ascertained via NanoVue $260 / 280$ and $260 / 230$ ratios.

For HBEC, total RNA was extracted using QIAGEN RNeasy Plus Kit (74034, Qiagen) following manufacturer's instructions. NanoDrop spectrophotometer was used to detect RNA quantity and purity. RNA purity was ascertained via NanoDrop 260/280 and 260/ 230 ratios.

\section{Reverse Transcription Quantitative PCR (RT-qPCR)}

1-2 $\mu \mathrm{g}$ of total cell RNA was reverse transcribed into cDNA using SuperScript VILO cDNA Synthesis Kit (11754050, Thermo Fisher). A volume corresponding to 25-50 ng of cDNA was used for each RTqPCR using Roche LightCycler 480 SYBR Green I Master (04707516001, Roche) sequence detection system. Each reaction was performed in triplicate.

Primer sequences $\left(5^{\prime}-3^{\prime}\right.$ orientation) were as follows:

Total ACE2 as described in (Ma et al, 2020).

Mouse ACE2_Forward: TCCATTGGTCTTCTGCCATCC. Mouse ACE2_Reverse: AACGATCTCCCGCTTCATCTC. Human ACE2_Forward: TCCATTGGTCTTCTGCCATCC. Human ACE2_Reverse: AACGATCTCCCGCTTCATCTC.

Specific primers for ACE2 isoforms as described in Blume et al (2021)

ACE2_Short_Fw: GTGAGAGCCTTAGGTTGGATTC.

ACE2_Short_Rv: TAAGGATCCTCCCTCCTTTGT.

ACE2_Long_Fw: CAAGAGCAAACGGTTGAACAC.

ACE2_Long_Rv: CCAGAGCCTCTCATTGTAGTCT.

Ribosomal protein large P0 (Rplp0) RNA was used as control transcript for normalization:

Mouse/Human Rplp0_Forward: TTCATTGTGGGAGCAGAC.

Mouse/Human Rplp0_Reverse: CAGCAGTTTCTCCAGAGC.

\section{Digital droplet PCR}

For HBEC, 200 ng of RNA was reverse transcribed into cDNA with iScript cDNA synthesis kit (1708890. Bio-Rad) following manufacturer's instructions.

ddPCR of 20 and 30 ng cDNA were performed using QX 200 ddPCR EvaGreen SuperMix according to standard protocols (Ludlow et al, 2014).

Primer sequences $\left(5^{\prime}-3^{\prime}\right.$ orientation) were as follows: ACE2 forward primer: TGTTGGGGAAATCATGTCACT. ACE2 reverse primer: GAGCAGGAAGTTTATTTCTGTTTCA.

Amplicon size was 112 nt. Primers were designed, via primerblast (Ye et al, 2012) and Roche assay design center, to be intron spanning and specific to ACE2 mRNA.

\section{Strand-specific real-time quantitative PCR}

Detection of tdilncRNAs was performed as previously described (Rossiello et al, 2017), with some modifications. Briefly, RNA samples were treated with DNase I (Thermo Scientific) at $37^{\circ} \mathrm{C}$ for 1 h. Next, $1 \mu \mathrm{g}$ of total RNA was reverse transcribed using the Superscript First-Stranded cDNA Synthesis Kit (Invitrogen) with strandspecific primers. cDNA was passed on a MicroSpin ${ }^{\text {TM }}$ G-50 columns (Cytiva), and qPCR was performed using SYBR Green I Master Mix (Roche). A volume of cDNA corresponding to $20 \mathrm{ng}$ of initial RNA 
was used. Each reaction was performed in triplicate. Rplp0 was used as a control gene for normalization.

qPCR primer sequences $\left(5^{\prime}-3^{\prime}\right.$ orientation):

Rplp0 Fw TTCATTGTGGGAGCAGAC.

Rplp0 Rv CAGCAGTTTCTCCAGAGC.

teloC Rv CCCTAACCCTAACCCTAA.

teloG Rv GGGTTAGGGTTAGGGTTA.

RT primer sequences $\left(5^{\prime}-3^{\prime}\right.$ orientation):

telo Fw CGGTTTGTTTGGGTTTGGGTTTGGGTTTGGGTTTGGGTT. telo Rv GGCTTGCCTTACCCTTACCCTTACCC TTACCCTTACCCT.

\section{Luciferase assay}

HeLa shTRF2 cells were treated with doxycycline to induce shTRF2 expression or with ionizing radiation (5 Gy). 5 or 1 day later, respectively, they were transfected with Lipofectamine 3000 Reagent (Thermo Fisher Scientific), accordingly to the manufacturer instruction, with ACE2(-1119)-luc plasmid, a gift from Gerhart Ryffel (Addgene plasmid \# 31110; http://n2t.net/ addgene:31110; RRID:Addgene_31110). Luciferase activity was measured $24 \mathrm{~h}$ post-transfection using the Luciferase Assay System (E4550, Promega) accordingly to the manufacturer instructions. Luciferase activity was normalized on total protein quantities.

\section{Single-cell transcriptomic analyses}

Single-cell transcriptomic data from aging tissues in the mouse lung were downloaded from Tabula Muris Senis (https://cellxgene. cziscience.com/collections/0b9d8a04-bb9d-44da-aa27705bb65b54eb, Almanzar et al, 2020). Seurat (v4.0.1, Hao et al, 2021) was used for downstream analyses.

\section{In silico transcription factor binding site analysis}

The tool Pscan (Zambelli et al, 2009) was used to look for overrepresented transcription factor binding site (TFBS) motifs in nucleotide sequences. TFBS motifs for the human Ace2 gene (refseq ID: NM_021804) were searched around $-450+50$ of the TSS, using the Jaspar 2018_NR matrix as a descriptor.

The EnrichR tool (Kuleshov et al, 2016) was used to perform a gene set enrichment analysis of the resulting Top100 significantly over-represented transcription factors.

\section{Statistical analyses}

Results are shown as mean \pm standard error of the mean (SEM). $P$ value was calculated by the indicated statistical tests, using Prism software. $P$-values for single-cell data analyses were calculated using the indicated statistical tests using the $\mathrm{R}$ software environment or with the default tests of the tools used.

\section{Data availability}

This study has not produced novel datasets.

Expanded View for this article is available online.

\section{Acknowledgements}

We thank Joachim Lingner and Marco Giorgio for sharing reagents and all F.d'A.d.F. laboratory members for discussions. S.S. is supported by Fondazione Umberto Veronesi (FUV) and was previously supported by SIPOD 2 (Structural International Post Doc Program 2) — the People Programme (Marie Curie Actions) of the European Union's Seventh Framework Programme FP7 under grant agreement no 600399. F.d'A.d.F laboratory is supported by: ERC advanced grant (TELORNAGING -835103); AIRC-IC (21762); Telethon (GGP17111); AIRC 5X1000 (21091); ERC PoC grant (FIREQUENCER - 875139); Progetti di Ricerca di Interesse Nazionale (PRIN) 2015 "ATR and ATM-mediated control of chromosome integrity and cell plasticity"; Progetti di Ricerca di Interesse Nazionale (PRIN) 2017 "RNA and genome Instability"; Progetto AriSLA 2021 "DDR \& ALS"; POR FESR 2014-2020 Regione Lombardia (InterSLA project); FRRB—Fondazione Regionale per la Ricerca Biomedica- under the frame of EJP RD, the European Joint Programme on Rare Diseases with funding from the European Union's Horizon 2020 research and innovation program under the EJP RD COFUND-EJP NO 825575. J.W.S. is supported by the lung cancer SPORE from NIH 50CA070907. The synopsis image has been created with BioRender.com.

\section{Author contributions}

SS, FR, and FdAdF conceptualized the study, designed the experiments, interpreted the results, and wrote the manuscript. SS, FR, VC, VM, CC, MC, EM, BRA, and AdL performed the experiments. Fl performed the bioinformatic analyses. ADN provided the human lung samples. JWS supervised BRA. CT supervised the histopathological analyses. FdAdF provided the funding for the study. All authors edited the manuscript.

\section{Conflict of interest}

F.R. and F.d'A.d.F. are inventors on the patent applications PCT/EP2013/059753 and PCT/EP2016/068162.

\section{References}

Aguado J, Sola-Carvajal A, Cancila V, Revêchon G, Ong PF, Jones-Weinert CW, Wallén Arzt E, Lattanzi G, Dreesen O, Tripodo C et al (2019) Inhibition of DNA damage response at telomeres improves the detrimental phenotypes of Hutchinson-Gilford Progeria Syndrome. Nat Commun 10: 4990-5000

Almanzar N, Antony J, Baghel AS, Bakerman I, Bansal I, Barres BA, Beachy PA, Berdnik D, Bilen B, Brownfield D et al (2020) A single-cell transcriptomic atlas characterizes ageing tissues in the mouse. Nature 583: 590-595 Aviv A (2020) Telomeres and COVID-19. FASEB J 34: 7247-7252

Barnes RP, Fouquerel E, Opresko PL (2019) The impact of oxidative DNA damage and stress on telomere homeostasis. Mech Ageing Deu 177: $37-45$

Beyerstedt S, Casaro EB, Rangel ÉB (2021) Barbosa Casaro E \& Bevilaqua Rangel É (2021) COVID-19: angiotensin-converting enzyme 2 (ACE2) expression and tissue susceptibility to SARS-CoV-2 infection. Eur J Clin Microbiol Infect Dis 40: 905-919

Blasco MA, Lee HW, Hande MP, Samper E, Lansdorp PM, DePinho RA, Greider CW (1997) Telomere shortening and tumor formation by mouse cells lacking telomerase RNA. Cell 91: 25-34

Blume C, Jackson CL, Spalluto CM, Legebeke J, Nazlamova L, Conforti F, Perotin J-M, Frank M, Butler J, Crispin M et al (2021) A novel ACE2 isoform is expressed in human respiratory epithelia and is upregulated in response to interferons and RNA respiratory virus infection. Nat Genet 53: 205-214

Bunyavanich S, Do A, Vicencio A (2020) Nasal gene expression of angiotensinconverting enzyme 2 in children and adults. JAMA 323: 2427-2429 
Celli GB, de Lange T (2005) DNA processing is not required for ATM-mediated telomere damage response after TRF2 deletion. Nat Cell Biol 7: 712-718

Chakravarti D, LaBella KA, DePinho RA (2021) Telomeres: history, health, and hallmarks of aging. Cell 184: 306-322

Chen J, Jiang Q, Xia X, Liu K, Yu Z, Tao W, Gong W, Han JDJ (2020) Individual variation of the SARS-CoV-2 receptor ACE2 gene expression and regulation. Aging Cell 19: 1-12

Crooke ST, Baker BF, Crooke RM, Liang X-H (2021) Antisense technology: an overview and prospectus. Nat Reu Drug Discou 20: 427-453

d'Adda di Fagagna F, Reaper PM, Clay-Farrace L, Fiegler H, Carr P, Von Zglinicki T, Saretzki G, Carter NP, Jackson SP (2003) A DNA damage checkpoint response in telomere-initiated senescence. Nature 426: 194-198

Dantuma NP, van Attikum H (2016) Spatiotemporal regulation of posttranslational modifications in the DNA damage response. EMBO J 35 : $6-23$

Demanelis K, Jasmine F, Chen LS, Chernoff M, Tong L, Delgado D, Zhang C, Shinkle J, Sabarinathan M, Lin $\mathrm{H}$ et al (2020) Determinants of telomere length across human tissues. Science 369: eaaz6876

Dicks N, Gutierrez K, Michalak M, Bordignon V, Agellon LB (2015) Endoplasmic reticulum stress, genome damage, and cancer. Front Oncol 5: 1-8

Francia S, Michelini F, Saxena A, Tang D, de Hoon M, Anelli V, Mione M, Carninci P, d'Adda di Fagagna F (2012) Site-specific DICER and DROSHA RNA products control the DNA-damage response. Nature 488: 231-235

Fumagalli M, Rossiello F, Clerici M, Barozzi S, Cittaro D, Kaplunov JM, Bucci G, Dobreva M, Matti V, Beausejour CM et al (2012) Telomeric DNA damage is irreparable and causes persistent DNA-damage-response activation. Nat Cell Biol 14: 355-365

Giorgio M, Stendardo M, Migliaccio E, Pelicci PG (2016) P66SHC deletion improves fertility and progeric phenotype of late-generation TERCdeficient mice but not their short lifespan. Aging Cell 15: 446-454

Grolimund L, Aeby E, Hamelin R, Armand F, Chiappe D, Moniatte M, Lingner J (2013) A quantitative telomeric chromatin isolation protocol identifies different telomeric states. Nat Commun 4: 2848

Guan W-J, Ni Z-Y, Hu YU, Liang W-H, Ou C-Q, He J-X, Liu L, Shan H, Lei C-L, Hui DSC et al (2020) Clinical characteristics of coronavirus disease 2019 in China. N Engl J Med 382: 1708-1720

Hamming I, Cooper M, Haagmans B, Hooper N, Korstanje R, Osterhaus A, Timens W, Turner A, Navis G, van Goor H (2007) The emerging role of ACE2 in physiology and disease. J Pathol 212: 1-11

Hao Y, Hao S, Andersen-Nissen E, Mauck WM, Zheng S, Butler A, Lee MJ, Wilk AJ, Darby C, Zager M et al (2021) Integrated analysis of multimodal singlecell data. Cell 184: 3573-3587.e29

Harley CB, Futcher AB, Greidert CW (1990) Telomeres shorten during ageing of human fibroblasts. Nature 345: 458-460

Herbig U, Jobling WA, Chen BPC, Chen DJ, Sedivy JM (2004) Telomere shortening triggers senescence of human cells through a pathway involving ATM, p53, and p21CIP1, but not p16INK4a. Mol Cell 14: 501-513

Hewitt G, Jurk D, Marques FDM, Correia-Melo C, Hardy T, Gackowska A, Anderson R, Taschuk M, Mann J, Passos JF (2012) Telomeres are favoured targets of a persistent DNA damage response in ageing and stressinduced senescence. Nat Commun 3: 708

Hoffmann M, Kleine-Weber H, Schroeder S, Krüger N, Herrler T, Erichsen S, Schiergens TS, Herrler G, Wu N-H, Nitsche A et al (2020) SARS-CoV-2 Cell Entry Depends on ACE2 and TMPRSS2 and Is Blocked by a Clinically Proven Protease Inhibitor. Cell 181: 271-280.e8

Huang C, Wang Y, Li X, Ren L, Zhao J, Hu YI, Zhang LI, Fan G, Xu J, Gu X et al (2020) Clinical features of patients infected with 2019 novel coronavirus in Wuhan, China. Lancet 395: 497-506
Huffman KE, Levene SD, Tesmer VM, Shay JW, Wright WE (2000) Telomere shortening is proportional to the size of the G-rich telomeric 3'-overhang. J Biol Chem 275: 19719-19722

Karimaian A, Majidinia M, Bannazadeh Baghi H, Yousefi B (2017) The crosstalk between $\mathrm{Wnt} / \beta$-catenin signaling pathway with DNA damage response and oxidative stress: Implications in cancer therapy. DNA Repair 51: $14-19$

Kuleshov MV, Jones MR, Rouillard AD, Fernandez NF, Duan Q, Wang Z, Koplev S, Jenkins SL, Jagodnik KM, Lachmann A et al (2016) Enrichr: a comprehensive gene set enrichment analysis web server 2016 update. Nucleic Acids Res 44: W90-W97

Lai T-P, Zhang N, Noh J, Mender I, Tedone E, Huang E, Wright WE, Danuser G, Shay JW (2017) A method for measuring the distribution of the shortest telomeres in cells and tissues. Nat Commun 81: 1-14

Lan J, Ge J, Yu J, Shan S, Zhou H, Fan S, Zhang QI, Shi X, Wang Q, Zhang L et al (2020) Structure of the SARS-CoV-2 spike receptor-binding domain bound to the ACE2 receptor. Nature 581: 215-220

Lee HW, Blasco MA, Gottlieb GJ, Horner JW, Greider CW, DePinho RA (1998) Essential role of mouse telomerase in highly proliferative organs. Nature 392: $569-574$

Lingappan K, Karmouty-Quintana H, Davies J, Akkanti B, Harting MT (2020) Understanding the age divide in COVID-19: Why are children overwhelmingly spared? Am J Physiol-Lung Cell Mol Physiol 319: L39-L44

Ludlow AT, Robin JD, Sayed M, Litterst CM, Shelton DN, Shay JW, Wright WE (2014) Quantitative telomerase enzyme activity determination using droplet digital PCR with single cell resolution. Nucleic Acids Res 42: 1-12

Lukassen S, Chua RL, Trefzer T, Kahn NC, Schneider MA, Muley T, Winter H, Meister M, Veith C, Boots AW et al (2020) SARS -CoV-2 receptor ACE 2 and TMPRSS 2 are primarily expressed in bronchial transient secretory cells. EMBO J 39: e105114

Ma D, Chen CB, Jhanji V, Xu C, Yuan XL, Liang JJ, Huang Y, Cen LP, Ng TK (2020) Expression of SARS-CoV-2 receptor ACE2 and TMPRSS2 in human primary conjunctival and pterygium cell lines and in mouse cornea. Eye 34: $1212-1219$

Michelini F, Pitchiaya S, Vitelli V, Sharma S, Gioia U, Pessina F, Cabrini M, Wang Y, Capozzo I, lannelli F et al (2017) Damage-induced IncRNAs control the DNA damage response through interaction with DDRNAs at individual double-strand breaks. Nat Cell Biol 19: 1400-1411

Monteil V, Kwon H, Prado P, Hagelkrüys A, Wimmer RA, Stahl M, Leopoldi A, Garreta E, Hurtado del Pozo C, Prosper F et al (2020) Inhibition of SARSCoV-2 Infections in Engineered Human Tissues Using Clinical-Grade Soluble Human ACE2. Cell 181: $905-913 . e 7$

Mullenders LHF (2018) Solar UV damage to cellular DNA: from mechanisms to biological effects. Photochem Photobiol Sci 17: 1842-1852

Okamoto K, Bartocci C, Ouzounov I, Diedrich JK, Yates JR, Denchi EL (2013) A two-step mechanism for TRF2-mediated chromosome-end protection. Nature 494: $502-505$

Palm W, De Lange T (2008) How shelterin protects mammalian telomeres. Annu Reu Genet 42: 301-334

Patel S, Rauf A, Khan H, Abu-Izneid T (2017) Renin-angiotensin-aldosterone (RAAS): The ubiquitous system for homeostasis and pathologies. Biomed Pharmacother 94: 317-325

Pessina F, Giavazzi F, Yin Y, Gioia U, Vitelli V, Galbiati A, Barozzi S, Garre M, Oldani A, Flaus A et al (2019) Functional transcription promoters at DNA double-strand breaks mediate RNA-driven phase separation of damageresponse factors. Nat Cell Biol 21: 1286-1299

Peters-Hall JR, Coquelin ML, Torres MJ, Laranger R, Alabi BR, Sho S, CalvaMoreno JF, Thomas PJ, Shay JW (2018) Long-term culture and cloning of 
primary human bronchial basal cells that maintain multipotent differentiation capacity and CFTR channel function. Am J Physiol - Lung Cell Mol Physiol 315: L313-L327

Piñeiro-Hermida S, Autilio C, Martínez P, Bosch F, Pérez-Gil J, Blasco MA (2020) Telomerase treatment prevents lung profibrotic pathologies associated with physiological aging. J Cell Biol 219: 1-21

Polo SE, Jackson SP (2011) Dynamics of DNA damage response proteins at DNA breaks: a focus on protein modifications. Cenes Dev 25: 409-433

Qiao Y, Wang X-M, Mannan R, Pitchiaya S, Zhang Y, Wotring JW, Xiao L, Robinson DR, Wu Y-M, Tien JC-Y et al (2021) Targeting transcriptional regulation of SARS-CoV-2 entry factors ACE2 and TMPRSS2. Proc Natl Acad Sci USA 118: e2021450118

Rossiello F, Aguado J, Sepe S, Iannelli F, Nguyen Q, Pitchiaya S, Carninci P, d'Adda di Fagagna F (2017) DNA damage response inhibition at dysfunctional telomeres by modulation of telomeric DNA damage response RNAs. Nat Commun 8 https://doi.org/10.1038/ncomms13980

Rudolph KL, Chang S, Lee HW, Blasco M, Gottlieb GJ, Greider C, DePinho RA (1999) Longevity, stress response, and cancer in aging telomerase-deficient mice. Cell 96: $701-712$

Vaiserman A, Krasnienkov D (2021) Telomere length as a marker of biological age: state-of-the-art, open issues, and future perspectives. Front Genet 11: $1816-1835$

Verity R, Okell LC, Dorigatti I, Winskill P, Whittaker C, Imai N, CuomoDannenburg G, Thompson H, Walker PGT, Fu H et al (2020) Estimates of the severity of coronavirus disease 2019: a model-based analysis. Lancet Infect Dis 20: 669-677

Walls AC, Park YJ, Tortorici MA, Wall A, McGuire AT, Veesler D (2020) Structure, function, and antigenicity of the SARS-CoV-2 spike glycoprotein. Cell 181: 281-292.e6

Wang D, Hu BO, Hu C, Zhu F, Liu X, Zhang J, Wang B, Xiang H, Cheng Z, Xiong $Y$ et al (2020) Clinical characteristics of 138 hospitalized patients with 2019 novel coronavirus-infected pneumonia in Wuhan, China. J Am Med Assoc 323: 1061-1069
Wang W, Mani AM, Wu Z-H (2017) DNA damage-induced nuclear factorkappa B activation and its roles in cancer progression. J Cancer Metastasis Treat 3: 45

Xudong X, Junzhu C, Xingxiang W, Furong Z, Yanrong L (2006) Age- and genderrelated difference of ACE2 expression in rat lung. Life Sci 78: 2166-2171

Yan R, Zhang Y, Li Y, Xia L, Guo Y, Zhou Q (2020) Structural basis for the recognition of SARS-CoV-2 by full-length human ACE2. Science 367: 1444-1448

Ye J, Coulouris G, Zaretskaya I, Cutcutache I, Rozen S, Madden TL (2012) Primer-BLAST: a tool to design target-specific primers for polymerase chain reaction. BMC Bioinformatics 13: 134-144

Yee M, David Cohen E, Haak J, Dylag AM, O'Reilly MA (2020) Neonatal hyperoxia enhances age-dependent expression of SARS-CoV-2 receptors in mice. Sci Rep 10: 1-14

Zambelli F, Pesole G, Pavesi G (2009) Pscan: Finding over-represented transcription factor binding site motifs in sequences from co-regulated or co-expressed genes. Nucleic Acids Res 37: 247-252

Zhao Y, Zhao Z, Wang Y, Zhou Y, Ma Y, Zuo W (2020) Single-cell RNA expression profiling of ACE2, the receptor of SARS-CoV-2. Am J Respir Crit Care Med 202: $756-759$

Zhou P, Yang X-L, Wang X-G, Hu B, Zhang L, Zhang W, Si H-R, Zhu Y, Li B, Huang C-L et al (2020) A pneumonia outbreak associated with a new coronavirus of probable bat origin. Nature 579: 270-273

Ziegler CGK, Allon SJ, Nyquist SK, Mbano IM, Miao VN, Tzouanas CN, Cao Y, Yousif AS, Bals J, Hauser BM et al (2020) SARS-CoV-2 receptor ACE2 is an interferon-stimulated gene in human airway epithelial cells and is detected in specific cell subsets across tissues. Cell 181: 1016-1035.e19

License: This is an open access article under the terms of the Creative Commons AttributionNonCommercial-NoDerivs License, which permits use and distribution in any medium, provided the original work is properly cited, the use is non-commercial and no modifications or adaptations are made. 